J OURNAL OF French and Francophone Philosophy
REV VE DE L A

philosophie française et de langue française

\title{
Pragmatism and Existential Philosophy
}

\section{Hans Lipps \\ Translation by Jason Hills}

Journal of French and Francophone Philosophy - Revue de la philosophie française et de langue française, Vol XVIII, No 1 (2008-2010) pp. 106-118.

\author{
Vol XVIII, No 1 (2008-2010) \\ ISSN 1936-6280 (print) \\ ISSN 2155-1162 (online) \\ DOI 10.5195/jffp.2010.174 \\ http://www.jffp.org
}

\section{(oc) EY-NC-ND}

This work is licensed under a Creative Commons Attribution-Noncommercial-No Derivative Works 3.0 United States License.

\section{ULIS D-Sunt}

This journal is published by the University Library System of the University of Pittsburgh as part of its D-Scribe Digital Publishing Program, and is co-sponsored by the University of Pittsburgh Press 


\title{
Pragmatism and Existential Philosophy
}

\author{
Hans Lipps \\ Translation by Jason Hills ${ }^{1}$
}

Existential philosophy determines the current situation of philosophy in Germany; it consummates the most complete separation with prior philosophy. Despite the diversity of its systems and points of view of previous philosophies, we recognize today the homogeneity of its aims and the persistence of its problems. It was guided by a tendency taken $a$ priori as natural that no longer suffices for the tendencies and aspirations that, in the thought of our time, urgently desire to surface. The fact that it is made up entirely of doctrines and systems appears to render it problematic. Perhaps no previous era "knew" those systems as well as ours, but the very fact that this philosophy can be transformed into pure and simple knowledge renders it suspect. We have learned not to trust what can be shown within the limits of reason, what can be contained within it, and what can be placed at the disposal of everyone and under the general shape of philosophy, ${ }^{2}$ without requiring any exertion or existential risk [risque d'existence]. ${ }^{3}$ We recognize today the non-obligatory character of these systems and doctrines.

The influence of Nietzsche and Kierkegaard is symptomatic of the current situation. ${ }^{4}$ Both were taken as outsiders in their days, because their thought differed so much from others. Here there are more doctrines and positions than one could ever prove or whose raison d'être could be discussed. It is an entirely new general attitude. It is not a thought content with solutions for freeing itself, as it were, from itself. Both Nietzsche and Kierkegaard attacked the "systems" in which everything seemed to them to be oversimplified and reduced to the trivial. They show how those systems move us away from the gravity of the problem that surfaced in the self, the reality of existence. The uncertain, tense, indefinite, fragmentary character of our temporal existence stands in contradiction with the totalizing nature that informs those doctrines. Both discovered how "inhuman" it is to begin 
from a "pure" subject of knowledge. For Nietzsche the will to create a system reveals a lack of honesty.

Here the question of knowing what philosophy "is" is posed anew. It frees itself from its union with science that goes back to Descartes. Knowledge, for Nietzsche and Kierkegaard, is "interpretation." It is an understanding that enlightens, a discovery that reveals those very depths of our existence which are originally hidden. Existential philosophy is not a doctrine; it can only be learned through experience. For, this new movement of thought opens the space through which reflection must travel, all the while knowing that it will not have a basis. We would only like to determine the direction of the path of this thought.

Kierkegaard said, "The philosopher of the system, as a man, resembles someone who builds a castle, yet who lives in the shed beside it. This fantastic being does not live in what he thinks, yet the thought of a man must be the house in which he lives." One can easily notice a certain affinity between the motifs of such a thought and those of pragmatism. When pragmatism, without allowing itself to be influenced by any point of view, undertakes an analysis of the practice of knowledge, what does it find there, if not the insignificance and the platitudes of such disputes as those of scholastic philosophy? Pragmatism, also, combats a philosophy that, in ignorance of its originary character, wanted to establish itself as science, but as a supreme science, as a science that has never been up to date and that has always remained behind; whereas positive science, within the limits in which it makes sense, arrived at some results. Pragmatism combats systematic philosophy in the same manner. In this combat, it neither discusses nor explains itself to the adversary to determine to what extent a point of view is right. Both [pragmatism and existential philosophy] separate themselves clearly from the beginning from their adversary, and without allowing the least discussion with them. The comparison between the two directions is all the more convincing since neither of them underwent the influence of the other. We will make a comparison between these two philosophies, so that in treating one, we will tackle the other; this will allow us to show the difference that appears in their overall structure, between these ways of philosophizing, by taking as the common denominator the progression of the ideas of each towards the notion of truth. Let us say it one more time: pragmatism and existential philosophy look to regain a connection to reality. Pragmatism resorts to practical experience that it contrasts with the outrageousness of the traditional conception of truth; existential philosophy, in its desire for intellectual honesty, makes its appeal to the earnestness of the individual. We will thus try to specify the domain of pragmatism and of existential philosophy. This domain is revealed by a specific spiritual attitude in each case. This spiritual attitude is either bound to certain requirements that pragmatism posits as 
being equivalent to the truth, or, in connection to existential philosophy, to the specific inquiry of the "real" ${ }^{5}$ truth that it proposes.

\section{II}

Criticism is however too easy a task for pragmatism. One must try hard to penetrate the great intentions of James and Dewey to recognize the nearness of pragmatism to the works of the young Nietzsche, for example, who speaks in his second "Untimely Meditation" of the "lazy in the garden of knowledge."

Dewey denounces the "prejudice that wants that what is ${ }^{6}$ exists only as being known by the mind in some manner," as if the structure of what is ${ }^{4}$ could consist only in the concept. Our primordial connection with things is not, for Dewey, knowledge. It is rather transaction [commerce] with things that is first given. One has them and experiences them, for example, in manipulating them, in wanting them, and in objecting to them as objects. They show themselves to me through their resistance. I notice the weather outside as it exerts an influence on my mood. We have experience of things solely through their continuity with practice. I do not need knowledge about a number written as a decimal; I must solely "know" of it, have at my disposal a know-how on the subject, possess the manner to write it, etc., in order to know how to count with it. But, knowledge in the proper sense of the word would signify that one retains something insofar as one understands or imagines it. Here a "lasting" possession was considered true. At first we act in connection with things, and we are right or not insofar as we know of them; error is a mistake. The way that I experience a thing is reflected in the manner and direction of my transaction with it. What is ${ }^{4}$ does not first have a structure conceived by the mind, as the object of knowledge that is always "represented" in whatever manner. Does not the word "comprehend" indicate the direction of "prehending," taking in hand, that is to say, understanding a thing to the point of knowing how to handle it? We never experience things in some isolated fashion as "objects," but always in the context of situations. The closest reality had always been subtracted. But, in this case, what does "knowledge" mean? One speaks of the "object" of knowledge. The thing to be known appears in the form of an encounter; it is thus an object only in a "temporary" way. Knowledge has an "episodic" character (Dewey). Knowledge always responds to a question: one examines, one watches up close, one contemplates intensively. The driving force of this heightened activity is always the difficulty in which one finds oneself that is due to the interruption of "knowing": one no longer knows how to handle things. Knowledge depends upon the reconstruction of this. Knowing is thus always surrounded by a horizon that is not on the same plane as knowledge, but that holds the knowing subject, leading one farther and guiding secretly. It is not by chance that one desires to know. There is no "pure," disinterested knowledge. One expects something from it, notably to be able to use things again. Each thing known relates to a 
particular natural situation. Whatever it may be or want, knowledge cannot go beyond the situation. Since knowledge brings us back to transaction with things, it has an "instrumental function" (Dewey).

It has been a question up to now of the "place" of knowledge. But how does it proceed? The distance that one takes, the division between subject and object, shows that one is thrown back upon oneself. Behind the abstract relations from which the theory of knowledge begins, pragmatism recognizes in attitudes, affections, etc., what happens from the "existential" point of view, the reality in which these relations are to be shown. One tries to analyze, to probe the object of knowledge. One looks to uncover the guiding clues with the intention of "coming to grips" with things. And what, at first, had been provisionally imagined and represented in that direction is then proven, as far as possible, by using it with things. The truth is in the resolution and in the elucidation of situations. A situation bears the mark of truth only if one is conscious of having surmounted the schism and of having recovered freedom of action. Knowledge and truth exist only in their subsequent effect, in the circumspection and clarity of practical experience, and in our transaction with things. The truth is in what originates and "is born" from intelligent action. It is not stable, because it is transformed by the direction in which the whole situation progresses. One cannot take possession of the truth through accumulating. The truth is only a means and must not be exaggerated by hypostasis into a definitive reality. It does not exist "in itself." It is only a bill of exchange that asks to be withdrawn. The truth does not consist in any kind of agreement with objects, but in the fact that some operations of understanding "correspond" to situations.

The truth is not in the individual, either. If the truth remains interior, it runs the danger of being lost. Due to its clarity from all perspectives, the truth is discovered in the "field" of action. In the field of action, one finds others again. My power, as well as my knowledge, is conditioned, that is, limited with respect to these others. One can have the purpose of one thing or not; we are only able to understand the truth together. Knowledge demands correction by others. The truth is thus not absolute either, in the sense that its origin depends on the mutual good will of those who communicate with each other, adjust their knowledge, and are transformed by that. Franklin said, "the man who recognizes his connection with others renounces all truth that reasons by itself." Every direct assertion destroys its communication, because assertions impede the response of the listener. The communication of truth becomes significant when its mobility and the danger it runs, due to the dogmatic obstinacy of the individual, are recognized. Indeed, the social psychology of Franklin contains, as was already demonstrated by Baumgarten, ${ }^{7}$ the seeds of pragmatism. It is a mentality, a way of thinking that secretly guides the style of American life. Pragmatism reflects something that appears in every day American life. 
Implicit in pragmatism is a very distinctive notion of life. It is addressed to the "common sense" of a person, the drive to develop reliable connections everywhere and to preserve them. It is an attitude that opposes itself to the exclusive possession of knowledge.

The fact that pragmatism contains this conception of life is revealed precisely by its sincere and authentic character. ${ }^{8}$ That is to say, pragmatism is not conceived exclusively through reason. Knowledge and truth are described there in their practical scope as a human affair. The way to understand and to interpret oneself, in a certain sense, and the motifs of its particular conception of the world and of life, are analyzed in an explicit fashion in pragmatism. It speaks to a person of a distinctive character, naturally and historically conditioned. Pragmatism is a supplement that philosophy gives to life. That is how-it is what one first notespragmatism differs so radically from systematic philosophy going back to Descartes.

It is through the image of the totality of being that these systems of philosophy want to address what truly is. ${ }^{9}$ This fact reinforces a distance from oneself. Even in their struggles and mutual criticisms, these philosophies remained joined to one another. It was above all the position of Descartes that always won. Certainly, human being also was always understood, in some manner, in its essence and in the drives of its existence. But this anthropological foundation was never recognized and only guided secretly the systematic philosophers. One thus began with a person who was not defined by the very structure of human nature, but who was considered as a simple given in formulas. For example, in regard to one's actions, such as knowledge, [the person was presumed] as a condition for the realization of it [knowledge]. But this "subject" of knowledge marks an inhuman position: the person is artificially constructed as a timeless being, as an Archimedean point where human being, in real isolation, would also have come off its hinges and been suspended in the air. The person is considered a rational being, who is in fact only the representative of that rationality. The person is cut from the fundamental origins of one's own being. The general point of view forgets the individual character of a person; the real existence of the individual is sacrificed to the timeless idea. Since Descartes, philosophy continues in the same manner as science. It shares the anonymity of the latter. It is representable by means of general ideas. ${ }^{10}$ Its problems, we say, are beyond time. We examine the correctness of its insights and of its knowledge. In relation to these philosophic systems, pragmatism brings an adjustment. It detects, for example, the secret motives and implications of science in its inquiry into the objectivity of knowledge and of truth. It is precisely here that it succeeds in discovering without difficulty the sign of the finite; only the being, who is always in some situation, can have the desire to free oneself from the particular character of these situations and can seek the means to make them available and usable 
everywhere, always and by everyone. The truth only becomes objective as a "means," inspired by "foresight" and placed at our disposal.

\section{III}

Pragmatism gets to the bottom of what really occurs in knowledge. It indicates the place that truth occupies in life and provides a correction to the traditional doctrine in the sense that it destroys its illusions. It wants to return to full reality. But existential philosophy does not want to be solely a critical attitude aiming to show the illusory character of an ideology. It is not content with a reflection that would correct and restore, like pragmatism, understanding and intelligibility-certainly a basis of general agreement not to be denied. The intellectual honesty of existential philosophy is more than a simple "honesty." Corresponding to the sincere and authentic ${ }^{11}$ question of pragmatism, there is in existential philosophy an effort to remain in the domain of reality itself and true. ${ }^{12}$ Existential philosophy does not want to clarify. It is precisely clarification that becomes irrelevant when this philosophy combats the "evaporation"13 that takes place in knowledge and know-how, insofar as those equate to an escape from the reality found in ourselves. A real return is opposed to reflection based on a precipitous interpretation. Existential philosophy shows the grave danger that a person dominated by science runs, and who, blinded against oneself, is deprived of one's ownmost possibilities. It does not adjust the facts, but calls to myself, places me ${ }^{14}$ in escaping my dislocation, ${ }^{15}$ seeing that I am not able to find my self in the place where philosophy was looking for it as a subject of knowledge. Kierkegaard wants to unintoxicate the individual; he wants to call the individual back to the reality of temporal existence to which one responds, the individual who had been lost in a general idea, such as reason or the "objective spirit." Nietzsche also desires a realism of human existence. It is not the ideals or conceptions of life that count for him, but penetrating unto the very depths of our conscious existence-the place of what touches me essentially and what, ordinarily, remains hidden under the surface.

Existential philosophy calls only to the individual and can neither be demonstrated and objectively analyzed, nor publicly exhibited. One calls for an interior effort, to which one completely devotes oneself in order to obtain, thanks to the "care" of oneself, a new basis.

This philosophy proceeds step by step. As a result of the crisis that springs from it, existential philosophy is opposed to philosophy since Descartes that always strived to find the right "method." Method is an objective way that one can teach and learn, this is to say, it is a manner of "taking objects in hand," of handling them, of practical advancement, and of obtaining safe results. In contrast, that [Cartesian] philosophy, because it presumed to look for the right method, because it wanted to establish itself as supreme science, that philosophy escaped, by the force of things, to itself. 
It renounced its own problems by characterizing them as the new special disciplines. Theory of knowledge, logistical doctrine, diverse schools of psychology owe their origin to the consequences of Descartes' position. This philosophy set aside the reality of my existence, this existence that spans from birth to death. It had been sacrificed to the abstract ideas growing outside of time, and, so to speak, halted, deprived of its tension and of its indefinite and fragmentary character.

The title of Heidegger's book is Being and Time. ${ }^{16}$ It poses anew the question of knowing what "being" is. One always understood in some vague manner when one was speaking of it, but it is put in an explicit way that one must place this average understanding at the disposal of everyone, by explicitly placing it within the horizon of the being of humankind. Existence understands itself in the diverse significations that it gives to what is. ${ }^{17}$ One can pose the question in two different ways:

1. How is it precisely that the constitution of my existence is learned from the diverse significations of what is ${ }^{15}$

2. How does the temporal condition of human existence inform the intrinsic possibility of our connection with the world, that is, from the point of view from which the world is presented to us?

We will briefly exhibit the second question. If one asks what is the temporal condition of our existence, we cannot put this existence in correspondence with time as we know it in its objective signification as present, future, etc. Because the signification of these, that is, the objective signification of a thing as being in the present for us, etc., is only the reflection of the temporal character of our existence. In existence time is "constituted," whereas things are only spread out "in" time constituted by that [existence].

In what sense is existence, in itself, temporal? We mean by existence the fundamental formal character of the human condition beyond the particularities of its anthropological and psychological kind. We "find" ourselves in existence, that is, it is impossible for us to get "behind" or "ahead" of ourselves in our existence for which we are answerable and with which we can only have relations. We are not masters of our existence, and thus not masters of ourselves, since we do not have command of our beginning. We have Being-in, ${ }^{18}$ that is, our existence is not a gift that one gives to us, but a task that is imposed on us. It goes thus, through each step of our existence, for ourselves. To exist means power, to have a possibility for existing that, because it was handed down to me, finds itself within the horizon of possibilities. Here is the experience that results from it: our life demands to be "directed." One throws oneself in a certain direction and understands, from this point of view, oneself. Each step of my existence 
means thus an interpretation of my being, insofar as it is an act of my articulation within the world, in some situation. And yet, the fact that I am not master of myself, since I cannot lay the grounds of my being, but am only able to take them up in the world, the fact that I exist always "already" and thus have overgrown the possibility of my existence, is disclosive of existence in its factual nature. It is the fact par excellence. That is, it [existence] is not a fact, as is generally understood, as what was created in time somewhere and then left behind its origin in time. It is how a hook became a hook from another thing. Previously, it did not exist yet. There was in its place a bit of iron. The fact that this hook exists afterwards in a certain location, in a certain time, shows that it became the prey of the context of the events, that it is conditioned by the situations that surround it. It has a "place" in time, that is to say, in the reality extended in time. But the factual nature of existence that consists in the temporal character of existence is completely different. Likewise, one cannot separate the event of finding oneself from the one of existence. To exist expresses itself directly in the fact of finding oneself. The temporal condition cannot be separated from existence.

As one must be, one throws oneself into some possibilities and one is ahead, or rather beyond oneself. But as it is about me, on the other hand, in the existence for which I am responsible, I move forward at each step of my existence, moving towards myself, or rather I come back to myself. And, one more time, I do not comport myself to some future, as one reckons in general with the future. It is not time that remains indefinite; it is me who is the indefinite. I discover myself as an unresolved question. But this responsibility of self, because one moves towards oneself, as being charged with one's existence, happens at the moment of decision. Existence becomes temporal $^{19}$ in being fulfilled step by step. It is temporal in an intrinsic manner, radically finite, because it is bound to itself by the fact that it moves towards itself. The temporal condition itself "makes" one be oneself. But the temporal condition of things means precisely the contrary of one such union with oneself. What they [things] are, they are through others, and time, for them, is a thing that leads them, carries them, and then abandons them.

If each step of existence means a responsibility taken upon itself,

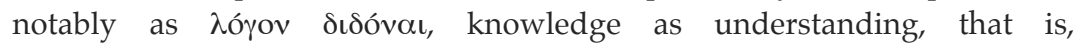
understanding of [(listening to)] things, is understood in advance. Knowledge occurs as an interpretation of oneself in situations. Existence realizes itself in concepts, in the sense that each conception is a realization ${ }^{20}$ of itself.

In knowledge, there is something. Knowledge does not have an end in itself. Pragmatism, likewise, did not accept that knowledge sets itself up as an advocate of a transcendent truth. Truth consisted however in an agreement with things, in an action that corresponded to the situation. But 
$\pi \rho \alpha \gamma \mu \alpha$ is an affair of everyone. One responds as an advocate of situations, which means that it is a question of rendering comprehensible and of explicating in what sense some thing is "correct" in given situations and in a given truth. One never forgets that a point of view, as correct as it is in the moment, can always be surpassed in the course of time. Explication within the world, in existential philosophy, is not a resolution of situations that would be, for it, fields of action. It is a question of being responsible for [(answering to)] oneself $f^{11}$ and then my interpretation has no end. Nietzsche says: existence is susceptible to an infinite interpretation, since it always forces itself into a new reality when it opens up, in light of the future, its own past. This is so because my past reveals itself to be my destiny that is never at the end of its path, but which one must always finish, and because one is a being undergoing development and always on the way towards oneself. One's connection with oneself can develop in two directions: one can either surrender or find oneself in one's own being. One becomes lost in what is not one's own being, if one moves away from oneself, in the forgetfulnes of oneself, through the pursuit of science without having understood the sense of one's activity. This is how Nietzsche saw the learnéd. To become true means to clarify existence. Honesty consists in seizing oneself in one's origins, "answering for oneself ${ }^{18}$ " in what one is truly. A situation is not an objective situation, that is, it is not a place on a field where one appears, where one finds oneself with others, where one meets them in their intentions, where I am unburdened of all care, where one can know for the other, where the truth is a thing in which everyone is interested. The situation that was handed down to me, in my destiny, cannot be "resolute" in that manner. No one can unburden me of anything, because I am the only one who is able to do something about it. Certainly, existential philosophy also emphasizes the considerable role that others play in the interpretation of life. It is precisely through others that I am able to be brought to myself, before myself, if others call to me to save me from that descent where I was sliding, to bring me back to the disclosure of myself. One is brought, returned to oneself by the other, and in this case the internal tendency of allowing oneself to be called by that other is compulsory.

The dialectic of Socrates, also, marks one such crisis and transformation. When Socrates asks what "is" this or that, he does not want to define concepts. He was talking of a $\tau \varepsilon \chi v \eta \mu \alpha \iota \varepsilon v \tau \iota \kappa \eta$; the interlocutor was to have been freed from an unconscious knowing that one was carrying in oneself. One was thus to have been brought to the explicit realization of oneself, to seize, in the understanding of one's being, one's own self. ${ }^{22}$ It was a question for Nietzsche of penetrating into the "original text" of human nature, and Kierkegaard spoke of an "original writing" of the relations of human existence that he desired to read again. It is what happens when existence, reading its own conceptions, attains some "anticipations," when it takes its basis in the creation of relations that find themselves articulated in some notions. One reaches oneself and one becomes-led step by step- 
conscious of oneself. The fact of "finding oneself caught," ${ }^{23}$ insofar as this is the expression of a crisis, reveals the specific philosophic emotion, the $\vartheta \alpha v \mu \alpha \zeta \varepsilon \iota v$ of Plato. Scientific philosophy did not know any emotion. It was a thing in which one was able to "be interested," but in which the interest was not in any way obligatory. If we previously called pragmatism a "supplement," it was in the sense of a clarification that was made through analysis. But, in existential philosophy, the supplementary ${ }^{24}$ and "posterior" character points to a necessary precedence of what can only guide the individual through the fact of being prior, in his explication within the world. This emotion of feeling "caught" is not a simply incidental circumstance, but is an integral part of the process of philosophizing that is only a return.

Is existential philosophy a "reflection on oneself?" Not in the common sense of the word that means that one thinks about oneself, examines one's own situation and connection with the world and humanity. Such is the reflection of Marcus Aurelius and Montaigne. Ideas, attitudes, and points of view are born here. They mature thanks to the experience acquired in life. "Idea" designates a fixed connection with a thing. One can keep or abandon one's ideas. They are belief or incredulity. One "arrives" in some manner at skepticism; reservation appears "recommended" or "obligatory," etc. The insatiable anxiety of existential philosophy is completely different; here the anxiety of our existence emerged; here one discovered oneself as an unresolved question. This reflection does not have any ground on which it could build its structure. Does the experimental character of the psychology of Kierkegaard, and the character of essay of the aphoristic philosophy of Nietzsche, oppose these philosophers to the precise and restricting notions of Heidegger, the representative of today's existential philosophy? His way of developing the structure of human existence, of fixing its framework in order to understand in this way the error and destiny of humanity in their intrinsic possibility, shows a know-how and a realization in the sense of an accomplished work. Is this a contradiction to what we had said previously, that existential philosophy cannot be revealed as a doctrine?

Let us examine Heidegger's language. This language shocks, because his expressions are, it seems, meticulous and forced. But could we point out that one is not upset with Aristotle for having created, for example, the

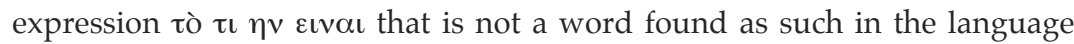
then spoken? One must note as a rule that only one who does not read Heidegger as he demands to be read is halted by his language. He needs to be read literally, to the letter, which is not obvious. One usually reads otherwise, e.g., in order to orient oneself and know the ideas of the other. One reads without thinking, but above all "between the lines" and the words. One understands what the author means; the author and reader meet on the level of an average understanding. Most things remain only 
half-said, and have no importance. The extent of philosophic expositions is fixed in large part by the traditions and the schools. "Subject," "object," "transcendental," etc.-it is at the level of everyone. But the fact that one must take Heidegger to the letter signifies the contrary of such a manner of reading. Not that one has to cling to the words, as if a description of material exactitude accounts for taking it literally. But one must hold on to each word in its signification as a word. It is quite another thing than the object of designation for which the word is usually employed. Heidegger calls for the search for the lost power of the word. It is about rediscovering the direction in which the word itself gives something to be understood, as one such indication of the word, no longer being objectively fixed, secretly guides us in the choice of a word, that is, in the struggle that one leads to give an adequate form to one's thought. Certainly, it is a very special final realization that words such as "care" ${ }^{25}$ and "finding oneself" ${ }^{26}$ receive. It is discovered only in the pursuit of a movement of thought, for which one can only appeal for the onset. The field of objective relations, which would already exist during and for the articulations from which language was first formed, is not implicated in this. The character, of unusual, forced, and shocking appearance, of the structures, phrases, and composed words protect us precisely from sliding into realizations as facile and common as that. The restrictive power of the concepts of "existential" 27 analysis are completely different from the exactitude of systematic notions. Because "exact" signifies "executed," and each systematic notion can easily be executed, that is, realized by definition. Through expressions such as "care" and "finding oneself," one is forcibly pushed back into the articulation of what one had already understood in the basis of existence.

The precise notions of Heidegger then come closer tothe "existential" analysis of the philosophy of Nietzsche and Kierkegaard. This is not a philosophy accessible to a person who "only thinks," for whom only things that can be raised to the transparency of reason have value-the only ones that person deigns to find suitable. "Existential" analysis is addressed to the individual who must bring something of oneself-who can be led solely towards something contained within oneself. Nothing is able to be expressed so directly. "It is an honor to understand me and that must be earned" (Nietzsche). Nietzsche and Kierkegaard searched for their reader. Heidegger also searches for a reader. What is the honesty of Nietzsche if not the enemy of an easy contentment that believes it possesses the truth by manipulating formulas and refusing to question itself?

1 This essay was originally published as Hans Lipps, "Pragmatisme et philosophie de l'existence," Recherches philosophiques 5 (1936-1937): 333-345. Rights to the translation are established 
under the definition of public domain in French law. The translator would like to thank Professors Véronique Maisier and Randall Auxier of Southern Illinois University Carbondale, and Director Larry Hickman of the Center for Dewey Studies at Carbondale for their support and assistance. Translation of Heideggerian terms in English has been correlated to: Martin Heidegger, Being and Time, trans. John Macquarrie \& Edward Robinson (San Francisco: HarperSanFrancisco, 1962). German terms and citations in endnotes are the author's and not the translator's.

2 In Formen des Allgemeinen.

3 Existentieller Einsatz.

4 Jaspers draws attention to the astonishing resemblance between Nietzsche and Kierkegaard, in their manner of thought, in the "reality of their thoughtful existence," in "their manner of understanding" (Vernunft und Existenz, Groningen, 1935).

5 Eigenlich.

6 Das Seiende.

7 E. Baumgarten, Benjamin Franklin und die Psychologie des amerikanischen (Alltags, Neue Jahrbücher, 1933), $251 \mathrm{ff}$.

8 Das Echte.

9 Das Seiende.

10 Mit Mitteln des Allgemeinen.

11 Dem Echten pragmatischen Fragens.

12 Sich in Eigentlichkeit hallen.

13 Verflüchtigung.

14 Stelli mich.

15 Aus meiner Verstellung.

16 Sein und Zeit.

17 Das Seiende.

18 Translator's note: "à être” is written as "Being-in" (In-Sein) per John Macquarrie and Edward Robinson's translation of Being and Time, although In-Sein is written être-à by Rudolf Boehm and Alphonse de Waelhens in their French translation by Gallimard.

${ }^{19}$ Zeitigt sich.

20 Aus-zeichnug.

21 Sich zu stellen.

22 It was characteristic, to the contrary, for the stance of a Franklin that made a method of the irony of Socrates, in wanting to lure, through an apparent lack of confidence, the interlocutor towards the arena, in order to give thus the possibility for the thing to emerge from manifold sides.

23

Betroflewwerden. 
Nachtvaglichkeit.

25

Sorge.

26

Befindlichkeit.

27 Existentiale Analytik. 